\title{
MIMO Antenna with Isolation Enrichment for 5G Mobile Information
}

\author{
Nithya $S$ and Seethalakshmi $V$ \\ KPR Institute of Engineering and Technology, Arasur, Coimbatore, India \\ Correspondence should be addressed to Nithya S; nithyashanmugam2488@gmail.com
}

Received 15 September 2021; Accepted 24 January 2022; Published 21 February 2022

Academic Editor: Jose F. Monserrat

Copyright (C) 2022 Nithya S and Seethalakshmi V. This is an open access article distributed under the Creative Commons Attribution License, which permits unrestricted use, distribution, and reproduction in any medium, provided the original work is properly cited.

\begin{abstract}
A wideband eight-input MIMO array antenna for a fifth-generation smartphone with high enhancement in element segregation is presented. The designed MIMO antenna array comprises eight E-shaped and inverted I-shaped slots on the material with good electrical and thermal conductivity, usually metal. To intensify the bandwidth, the required resonances can be obtained by adjusting the E-shaped slots. Furthermore, to boost the element shielding of the MIMO array antenna system, a single-ended spanner-shaped slot is introduced between each antenna element. As a result, all the elements can cover a wide bandwidth with a frequency range of $3.3 \mathrm{GHz}$ to $6 \mathrm{GHz}$. The isolation is boosted to $20 \mathrm{~dB}$ by a single-ended spanner-shaped slot, and the ECC below 0.04 is measured between any two elements, which show agreeable impedance in far zone radiation characteristics. In the proposed system design, the coupling is induced by the current over a surface on a metallic frame between two antenna components. Consequently, two elements of antenna were separated with an etched slot engraved on a metal frame and used a unique wrench-like resonator to limit the surface current; even though this arrangement increases the free surface of the antenna, it can effectively reinforce the insulation of the element. The performance of the proposed system analyzed certain antenna radiations by handset and head versions. As a consequence, the efficiencies of antennas 2, 3, and 5 are less than $60 \%$, the efficiencies of antenna 8 are around $60 \%$, and the efficiencies of antennas 1, 4, 5, 6, and 7 are even more than $60 \%$. The proposed wideband MIMO antenna device demonstrates reasonably good isolation and low envelope correlation coefficient, both of which are pretty good for fifth-generation MIMO antenna application. The calculated findings show that the planned antenna array's operating frequency range is capable of covering 3.3 to $6 \mathrm{GHz}$, with over $20 \mathrm{~dB}$ isolation. The antenna will guarantee that the ECC level is smaller than 0.04. The proposed MIMO antenna technology is also efficient for mobile terminal 5G applications.
\end{abstract}

\section{Introduction}

Over the last few years, phenomenal improvement of telecommunication has depleted the potential of existing $4 \mathrm{G}$ mobile communication systems. Recently developed communication technology is paying attention to delivering high throughput with minimal time and energy wastage [1]. There is no question that one of the key metrics for potential $5 \mathrm{G}$ connectivity would be the data transfer rate. Merchandising of fifth-generation (5G) mobile connectivity, broadband data, and smart mobile networks is nearing [2]. However, there are problems with $5 \mathrm{G}$ technology; for example, highspeed demand for the wireless networks MIMO and broadband are needed to address this issue in order to enhance the capacity of the channel and efficiency by exploiting the properties of multipath without changing the power at the input [3]. In comparison with the traditional mobile telephone, $5 \mathrm{G}$ mobile phones favour MIMO antenna systems such as 2-, 4-, 8-, 10-, and 12-array antenna systems. Furthermore, the MIMO system should possess the features of broadband and isolation characteristics to lead to a good success. Different nations and operators have set up different frequency bands for $5 \mathrm{G}$ communication like the USA with a low and midband of $3700 \mathrm{MHz}-4200 \mathrm{MHz}$ and a high band of $64 \mathrm{GHz}-71 \mathrm{GHz}$, Korea with a high band of 26.5 $\mathrm{GHz}-29.5 \mathrm{GHz}$, and India with a low and medium band of $3400 \mathrm{MHz}-3600 \mathrm{MHz}$ and a high band of 24.5 $\mathrm{GHz}-29.5 \mathrm{GHz}$. Broadband is a crucial feature in $5 \mathrm{G}$ 
applications to cover these frequency bands. It is our understanding that the efficiency of the MIMO antenna system will be adversely affected by the mutual coupling of each antenna element. As a result, building a reliable MIMO antenna system to improve element insulation is a challenge. What is more, integrating such a MIMO system into a smart mobile phone with a restricted frame in space is rather difficult [4]. Although the huge 5G antenna is far more competent of enhancing the spectrum efficiency and the data rate, mounting multiple elements in a highly restrictive space in a mobile phone is not an easy task.

The proposed compact on-chip antenna is fabricated on a stack of five layers comprising metal silicon. The top silicon layer is sandwiched with two very thin metal layers made of aluminum. The parallel metal layers sandwiching the silicon layer are perforated with a periodic arrangement of circular slot holes, and the two outer edges of the metal layers are connected to each other with metal pins through the silicon layer to create the SIW structure [5]. The top layer consists of a $2 \times 4$ array of rectangular copper patches. Etched on the patches is a row of subwavelength circular slots. The antenna is excited using proximity coupling at the patch edge, which is analogous to a gap coupling patch. This is achieved with a microstrip coplanar waveguide feedline, which is created by having both sides next to the feedline grounded. The feedline is sandwiched between the two silicon oxide layers, below which is a layer with aluminum patches that are separated from each other by a narrow gap. This layer acts like a partially reflective surface [6]. With the proposed technique, the isolation between the radiating elements was improved on average by $22.5 \mathrm{~dB}$ compared to a reference array antenna with no SIW isolation. The performance of the array was enhanced by transforming the patch to exhibit metamaterial characteristics. This was achieved by embedding the patch antennas in the array with subwavelength slots [7]. It is shown that the issues mentioned above afflicting on-chip antennas can be reduced by applying the $2 \mathrm{D}$ composite right/left-handed (CRLH) metamaterial transmission line (TL) known as the metasurface concept in the development of the antenna [8]. The performance of the proposed technique, when compared with the conventional on-chip antenna designs, shows improvement in the impedance bandwidth, radiation gain, and efficiency [9].

Decoupling technique and the process of making antenna smaller have become an underlying requirement for the design of antenna to satisfy the requirements of a wellpacked antenna layout and to increase insulation or isolation. However, more extreme mutual coupling would result in higher antenna elements and lesser distance to one another, thereby degrading the performance of the MIMO antenna system [10]. So, reducing the reciprocal coupling is the main challenge in developing the MIMO array $[11,12]$. To fix the issue of separation, several decoupling methods have been implemented. For example, to improve the insulation of the system with a large gap between each antenna element, spatial diversity and polarization diversity were used $[13,14]$. To make up the eight-antenna MIMO series, four compact two-antenna construction structures are employed in [15]. Along with the eight elements, the capacity of the channel is greatly improved, but the insulation is only $10 \mathrm{~dB}$. Furthermore, a network of sixteen antennas was studied, which raised the channel bandwidth to $71 \mathrm{bps} / \mathrm{Hz}$ [16]. Three neutralization lines guarantee the isolation of $10 \mathrm{~dB}$. A $2 \times 2$ MIMO monopolistic array with a ground-based decoupling structure has been studied in [17]. This covers the high isolation (more than $20 \mathrm{~dB}$ ) and low ECCC band of $22-248 \mathrm{GHz}$ (below 0.01). In the meantime, broadband dual antenna structure has been investigated [18], with the use of three neutralization lines to provide segregation which is also adopted in [19]. To reduce mutual coupling in a $2 \times 2 \mathrm{MIMO}$ device to a minimum, EBG (electromagnetic bandgap) structure [20, 21] was used, and to reduce mutual coupling, further resonators or hybrid resonators [22-24] were used.

This technique is shown to effectively reduce mutual coupling between adjacent radiation elements that can otherwise undermine the arrays radiation gain and pattern. The periphery of each patch is embedded with circular dielectric slots, which are created based on the metasurface concept to enhance the radiation gain and efficiency performances [25]. The advantages of the proposed technique are as follows: (i) simplicity; (ii) cost-effectiveness as there is no need for short-circuited via-holes or three-dimensional metal walls; and (iii) ability to be retrofitted in existing array antennas [26]. An effective method is presented for suppressing mutual coupling between adjacent radiating elements, which is based on metasurface isolation for multiple-input multiple-output (MIMO) and synthetic aperture radar (SAR) systems. This is achieved by choking surface current waves induced over the patch antenna by inserting a cross-shaped metasurface structure between the radiating elements [27]. Two patch antennas are electromagnetically coupled through the substrate media and space above and below it. Coupling on the substrate layer is due to surface waves, and the coupling through the air is through direct patch-to-patch near field [28]. One of the two couplings is more dominant, which depends on the spatial geometry of the antenna structure. Direct mutual coupling between the patch elements can be controlled by adding an extra indirect coupling path using the proposed EBG-MTM isolation structure [29]. Multiple-input multiple-output (MIMO) systems enable high-capacity wireless communications without increasing the signal bandwidth or signalto-noise ratio (SNR). This is because the multiple data streams can be transmitted simultaneously by using multiple antennas (antenna array) at the transmitter and receiver [30]. To realize compact MIMO antennas, the critical challenge is to minimize the signal correlation between antennas over a wide frequency range. When multiple antennas are placed close, the mutual coupling can degrade the radiation performances of the antennas and the channel capacity of MIMO systems [31].

In [17], between the antenna elements, an inverted I ground slot with enhanced element segregation of $20 \mathrm{~dB}$ has been introduced. A multimode decoupling element similar to a tree has been registered in [32], and broadband isolation has been carried out, but it is still bulky and has no easy adjustment features; in principle, due to the extremely 
complicated electromagnetic (EM) setting, a multimode resonator of miniaturized size (decoupling element) is difficult to regulate. The majority of decoupling networks are of filter type [11,33-35]. Hence, it is possible to realize multidecoupling modes by referring to the multimode filter theory of architecture. To achieve pattern diversity, the methodology outlined in [36] uses a ring slot, which ensures isolation in excess of $15 \mathrm{~dB}$ between the ports of larger size $\left(80 \times 80 \mathrm{~mm}^{2}\right)$. To boost the separation, a variety of decoupling structures or various stubs were employed between any two radiators. To achieve pattern and polarization diversity, feeding directions with perpendicular arrangement were employed in [37-40]. In this paper, isolation enrichment with an eight-input MIMO array antenna for a fifth-generation smart mobile system is presented. E-shaped and inverted I-shaped slots were carved on the metal frame for exploring new radiation methods in the design of MIMO smart mobile phone antenna space-restricted, in contrast to other models, affected by the limited radiation-induced environment of the metal structure. To improve the insulation of the components of the MIMO array antenna system, a one-end wrench slot was suggested. Consequently, the wide spectrum of the MIMO array antenna system is obtained, and the isolation of the element is around 20, which can cover a larger part of the range of less than $6 \mathrm{GHz}$. As in Table 1, the suggested fifth-generation MIMO array antenna system outperforms the state of technology in this area.

\section{Design of MIMO Antenna}

Multiple-input-multiple-output (MIMO) antennas with the ability to radiate waves in more than one pattern and polarization play a great role in modern telecommunication systems. This paper provides a theoretical review of different mutual coupling reduction techniques in MIMO antenna systems. The increase in the mutual coupling can affect the antenna characteristics drastically, thus degrading the performance of the MIMO systems. It is possible to improve the performance partially by calibrating the mutual coupling in the digital domain. A millimeter-wave (MMW) antenna is presented for the fifth-generation (5G) wireless multipleinput multiple-output (MIMO) applications in order to offer numerous advantages, including compactness, planar geometry, high bandwidth, and high gain performance. The concept of defected ground structures has been deployed for the first time in MIMO antenna design at the MMW spectrum to fulfil $5 \mathrm{G}$ requirements of high bandwidth with compactness and low design complexity. The top surface of the antenna comprises a coplanar waveguide-fed T-shaped radiating patch element, while the bottom part is designed to constitute a partial ground loaded with two iterations of symmetrical split-ring slots at an optimized distance. The general view of the $5 \mathrm{G}$ MIMO antenna device designed to fit the $5 \mathrm{G}$ smart mobile phone framework is shown in Figure 1(a).

The field scale is $150 \times 80 \mathrm{~mm}^{2}$, and the handset is with a thickness of $7 \mathrm{~mm}$. To create the body of the smartphone, an
FR4 substrate with a thickness of $0.8 \mathrm{~mm}$, relative permittivity of 4.4, and tangent loss of 0.02 is used. For the manufacture of the frame and the circuit board, whose relative permittivity is 4.4 and the loss tangent is 0.02 , the $0.8 \mathrm{~mm}$ thick FR4 substrate is used, and copper for the radiation element (conductivity $5.8 \times 10^{7} \mathrm{~S} / \mathrm{m}$ ) is used. Copper conductivity is very robust, and it has no effect on the matching of impedance. The size of the antenna substrate is $150 \times 80 \times 7 \mathrm{~mm}^{3}$, which is compatible with a mobile phone.

The structure of slot antenna 1 (Ant 1) and antenna 2 (Ant 2) is illustrated in Figures 1(b) and 1(c). The 8-slot antenna part arrangement is as follows. The 1, 3, 5, and 7 and 2, 4, 6, and 8 antennas are arranged vertically along the two sides of the PCB (right and left). Every antenna part can completely cover the $3.3 \mathrm{GHz}$ to $5 \mathrm{GHz}$ band in this design. As can be seen, the $14 \mathrm{~mm} \times 27 \mathrm{~mm}$ E-shaped slot is first engraved on the surface of the ground, which serves as the main radiator of the multiband antenna. The inverted "I" shape is formed by slicing a $16 \mathrm{~mm} \times 5.5 \mathrm{~mm}$ opening section over an E-shaped slot. The E-shaped slot that is couple-fed by an inverted L-shaped feed strip is merely $11.8 \mathrm{~mm}$ displaying that the antenna function offered has an adequate size for a smart mobile phone.

The feeding strip consists of 2 parts, namely, the $11.8 \mathrm{~mm} \times 1.5 \mathrm{~mm}$ vertical segment $(50 \mathrm{ohm}$ microstrip feed line) and a small horizontal adjustment section or an adjustment tip stretching from a point, with a dimension of length $L(\mathrm{~mm}) \times$ width $\mathrm{W} \mathrm{mm}$. The slot antenna element suggested is well energized and balanced by regulating the length $L$, width $\mathrm{W}$, and the relative position of the adjusting section. The simulation tool is able to accomplish these slot parameters $\left(L_{1}, L_{2}\right.$, and $\left.L_{3}\right)$ and the separation distance between them. To achieve maximum efficiency of the suggested MIMO antenna array, two dissimilar mechanisms were implemented. The slot parameter of the antenna $L_{1}(\mathrm{~mm}), L_{2}(\mathrm{~mm})$, and $L_{3}(\mathrm{~mm})$ was varied from each antenna element, as shown in Table 2. The antenna element is a kind of open slot, and four resonance modes are energized by means of E-shaped slots that are dependent heavily on its nearby terrain. To attain a stronger performance agreement, antenna elements are arranged differently with different dimensions, which are reformed and defined effectively.

A simpler and faster method than the one previously described derives the correlation coefficient from the $S$ parameters of the antennas, that is, the port reflection coefficients S11 and S22 of the two antennas, and the coupling S21 $=$ S12. Several publications present the relation between the $S$ parameters and the correlation coefficient.

Total radiated powers for the two antennas are

$$
\begin{aligned}
& P_{\text {rad }}, 1=(1-|S 11| 2-|S 21| 2) \eta 1, \\
& P_{\text {rad }}, 2=(1-|S 22| 2-|S 12| 2) \eta 2,
\end{aligned}
$$

from which the definition of radiation efficiencies $\eta 1$ and $\eta 2$ is clear. Internal losses for the two antennas are from this concluded to be given by 
TABLE 1: Comparative rendering with previously published literature.

\begin{tabular}{|c|c|c|c|c|c|c|c|}
\hline Reference & Antenna element size & Decoupling method & Isolation & ECC & $\begin{array}{c}\text { Effective bandwidth } \\
(\mathrm{GHz})\end{array}$ & $\begin{array}{c}\text { Total } \\
\text { efficiency } \\
(\%)\end{array}$ & Complexity \\
\hline Proposed & $\begin{array}{l}150 \times 80 \times 7 \mathrm{~mm}^{3} \\
\text { (eight elements) }\end{array}$ & Ground slot & 20 & $<0.04$ & $3.3 \mathrm{GHz}-5.82 \mathrm{GHz}$ & $50-92$ & Simple \\
\hline [4] & $\begin{array}{l}150 \times 75 \times 7 \mathrm{~mm}^{3} \\
\text { (eight elements) }\end{array}$ & Ground slot & $>18$ & $<0.05$ & $3.3 \mathrm{GHz}-6.0 \mathrm{GHz}$ & $40-90$ & Complex \\
\hline$[12]$ & $\begin{array}{c}17.4 \times 6 \times 0.8 \mathrm{~mm}^{3} \\
(\text { single element })\end{array}$ & No & $>19.6$ & $<0.013$ & $3.0 \mathrm{GHz}-6.0 \mathrm{GHz}$ & $49-76.9$ & Complex \\
\hline$[17]$ & $\begin{array}{l}124 \times 74 \times 6 \mathrm{~mm}^{3} \\
\text { (eight elements) }\end{array}$ & $\begin{array}{l}\text { Hybrid method } \\
\text { (neutralization line and } \\
\text { ground slot) }\end{array}$ & $>15$ & $<0.15$ & $3.3 \mathrm{GHz}-3.6 \mathrm{GHz}$ & $40-60$ & Simple \\
\hline [20] & $\begin{array}{c}150 \times 80 \times 0.8 \mathrm{~mm}^{3} \\
(\text { eight elements })\end{array}$ & Ground slot & $>11$ & $<0.15$ & $3.4 \mathrm{GHz}-3.8 \mathrm{GHz}$ & & \\
\hline $5.15 \mathrm{GHz}-5.9 \mathrm{GHz}$ & $45-65$ & Simple & & & & & \\
\hline$[22]$ & $\begin{array}{c}150 \times 75 \times 0.8 \mathrm{~mm}^{3} \\
(\text { eight elements) }\end{array}$ & Neutralization line & 10 & $<0.32$ & $3.3 \mathrm{GHz}-3.6 \mathrm{GHz}$ & $40-52$ & Simple \\
\hline [23] & $\begin{array}{c}150 \times 80 \times 0.8 \mathrm{~mm}^{3} \\
(\text { eight elements })\end{array}$ & No & $>17.5$ & $<0.05$ & $3.3 \mathrm{GHz}-3.6 \mathrm{GHz}$ & $62-76$ & Simple \\
\hline$[32]$ & $\begin{array}{l}150 \times 75 \times 8 \mathrm{~mm}^{3} \\
\text { (eight elements) }\end{array}$ & Polarization orthogonal & $>17$ & $<0.1$ & $3.4 \mathrm{GHz}-3.6 \mathrm{GHz}$ & $49-72$ & Moderate \\
\hline$[34]$ & $\begin{array}{l}145 \times 75 \times 6 \mathrm{~mm}^{3} \\
\text { (eight elements) }\end{array}$ & No & $>15$ & $<0.16$ & $3.4 \mathrm{GHz}-3.6 \mathrm{GHz}$ & $42-73$ & Complex \\
\hline [7] & $\begin{array}{c}150 \times 75 \times 6.8 \mathrm{~mm}^{3} \\
\text { (eight elements) }\end{array}$ & No & $>14.7$ & $<0.05$ & $3.3 \mathrm{GHz}-5.0 \mathrm{GHz}$ & $46-80$ & Complex \\
\hline [9] & $\begin{array}{c}36 \times 36 \times 1.9 \mathrm{~mm}^{3} \text { (four } \\
\text { elements) }\end{array}$ & Pattern diversity & $>10.8$ & $<0.08$ & $3.4 \mathrm{GHz}-3.6 \mathrm{GHz}$ & $62-80$ & Complex \\
\hline [25] & $\begin{array}{c}160 \times 68 \times 0.8 \mathrm{~mm}^{3} \\
(\text { eight elements })\end{array}$ & Pattern diversity & 15 & $<0.15$ & $3.3 \mathrm{GHz}-5.0 \mathrm{GHz}$ & $68-82$ & Medium \\
\hline
\end{tabular}
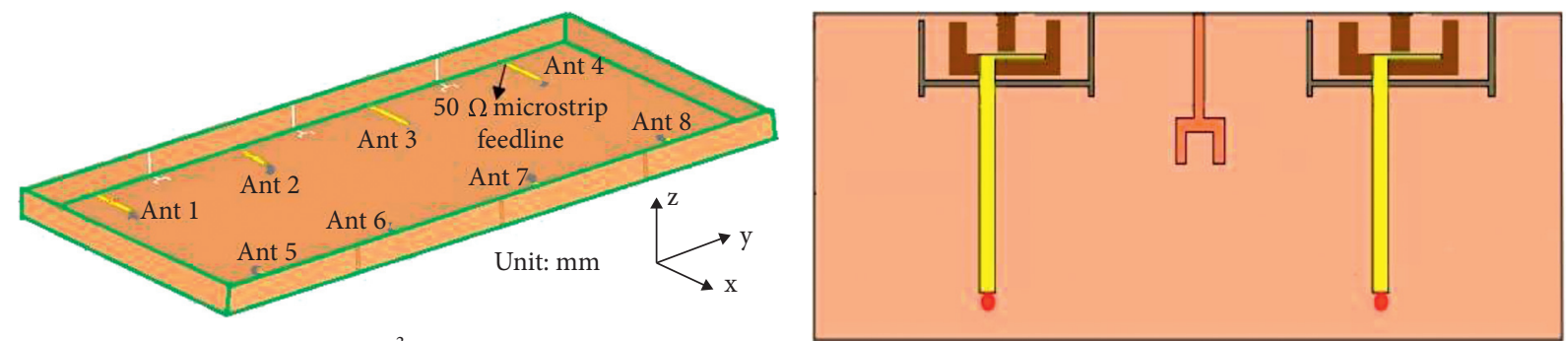

Antenna system: $150 \times 80 \times 7 \mathrm{~mm}^{3}$

$\square$ Metal strip

Metal sheet

(a)

(b)

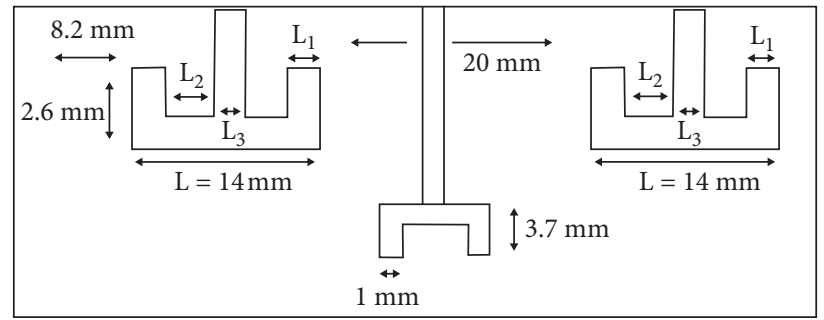

(c)

Figure 1: (a) General view of 5G MIMO antenna. (b) 5G MIMO antenna with feed line and decoupling element. (c) Dimensions of 5G MIMO antenna with feed line and decoupling element. 
TABLe 2: Variations of $L_{1}, L_{2}$, and $L_{3}$ of E slot element.

\begin{tabular}{lcc}
\hline$L_{1}(\mathrm{~mm})$ & $L_{2}(\mathrm{~mm})$ & $L_{3}(\mathrm{~mm})$ \\
\hline 2 & 1 & 4.5 \\
2.5 & 2 & 3.5 \\
3 & 2.4 & 2.8 \\
3.5 & 2 & 2.5 \\
4 & 2 & 2.0 \\
\hline
\end{tabular}

$$
\begin{aligned}
P_{\text {loss }}, 1 & =(1-|S 11| 2-|S 21| 2)(1-\eta 1), \\
P_{\text {loss }}, 2 & =(1-|S 22| 2-|S 12| 2)(1-\eta 2), \\
0 & =\frac{S_{11} S_{12}^{*}+S_{21} S_{22}^{*}}{\sqrt{\left(1-\left|S_{11}\right|^{2}-\left|S_{21}\right|^{2}\right)\left(1-\left|S_{22}\right|^{2}-\left|S_{12}\right|^{2}\right)+\rho_{\text {rec }} \sqrt{\eta_{1} \eta_{2}}}+\rho_{\text {loss }} \sqrt{\left(1-\eta_{1}\right)\left(1-\eta_{2}\right)}} .
\end{aligned}
$$

Since the expression on the right-hand side in the above equation is zero, one unknown term can be calculated if the other terms are known. The principle of the method of calculating received signal correlation from $S$ parameters is to measure the first term and take the second term to be the negative of this value.

S21: the measured $\mathrm{S}$ parameter is $26 \mathrm{~dB}$ at $3.5 \mathrm{GHz}$, $22 \mathrm{~dB}$ at $4.5 \mathrm{GHz}$, and $20 \mathrm{~dB}$ at $5.5 \mathrm{GHz}$.

S32: the measured $\mathrm{S}$ parameter is $23 \mathrm{~dB}$ at $3.5 \mathrm{GHz}$, $32 \mathrm{~dB}$ at $4.5 \mathrm{GHz}$, and $47 \mathrm{~dB}$ at $5.5 \mathrm{GHz}$.

S31: the measured $\mathrm{S}$ parameter is $25 \mathrm{~dB}$ at $3.5 \mathrm{GHz}$, $21 \mathrm{~dB}$ at $4.5 \mathrm{GHz}$, and $20 \mathrm{~dB}$ at $5.5 \mathrm{GHz}$.

S51: the measured $\mathrm{S}$ parameter is $26 \mathrm{~dB}$ at $3.5 \mathrm{GHz}$, $30 \mathrm{~dB}$ at $4.5 \mathrm{GHz}$, and $32 \mathrm{~dB}$ at $5.5 \mathrm{GHz}$.

To examine the resonant mechanisms, create slots by regulating the electrical length of $\mathrm{E}$ and $\mathrm{I}$. However, the antenna with $\mathrm{E}$ and I slots resonates at 4 different frequencies

Figures 2(a) and 2(b) show that the 1st resonance spreads predominantly around the E-shaped slots. The 2nd and 3rd resonance surface currents are primarily concentrated in the slot of "I shape." However, the 4th resonance originates from the mating between the E- and I-shaped slots. By changing the electrical length of unaltered I-shaped slots, we studied the resonant mechanisms. It is found that the resonance changes to high frequency in the $1 \mathrm{st}, 2 \mathrm{nd}, 3 \mathrm{rd}$, and $4 \mathrm{th}$, while the $3 \mathrm{rd}$ resonance remains unchanged. In contrast, the length of I-shaped slots is increased, and the length of E-shaped slots is kept unaltered. The $2 \mathrm{nd}, 3 \mathrm{rd}$, and 4 th resonances explicitly shift to a lower frequency, while the 1st resonance stays unchanged. We can infer that the first resonance comes from the E-shaped slot, the second and third resonance can come from I-shaped slots, the fourth resonance is born from the E- and I-shaped slots coupling. Finally, a frequency range from $3.3 \mathrm{GHz}$ to $6 \mathrm{GHz}$ can support the proposed antenna feature, with a reflection coefficient lesser than the standing wave ratio of $-6 \mathrm{~dB}(3: 1)$ voltage.

\section{Decoupling Element}

The main idea of the decoupling algorithm proposed by Boksenbom and Hood is making the overall closed-loop transfer function of the controlled MIMO system diagonal. So far, this is still the primary solution to the coupling problem. Some other remarkable contributions have been made based on this idea. For single-input-single-output (SISO) systems, there is a widely accepted time delay compensation algorithm named Smith Predictor. This compensation algorithm was improved to be applicable to MIMO systems with multivariable delays by Ogunnaike and Ray under some specified assumptions. Other developments aiming at multivariable Smith Predictor can be found. These decoupling methods are mainly focused on systems with multivariable delays. These decoupling methods tried to make the MIMO system decoupled first, so the interactive MIMO system control problem would be transformed into multiple single loops system control problems. Then, the Smith Predictor can be designed based on the decoupled system. However, the uncertain accuracy of the predictor, unrealizable matrix inversion expression, and complicated decoupling procedure have kept Smith Predictor decoupling away from being extensively applied in industrial processes.

Here, a variety of decoupling techniques were initiated to improve the separation between each of the two antenna components. In our design, the coupling is induced by the current over a surface on a metallic frame between two antenna components. Consequently, two elements of antenna were separated with an etched slot engraved on a metal frame and used a unique wrench-like resonator to limit the surface current; even though this arrangement increases the free surface of the antenna, it can effectively reinforce the insulation of the element.

For the MIMO array antenna system, this approach is recommended with a larger requirement of isolation but low clearing restriction. Our decoupling-free design can also satisfy the demand for the requirement of the antenna with very restricted clearance but with less segregation requirement. In order to check the element decoupling mechanism, 


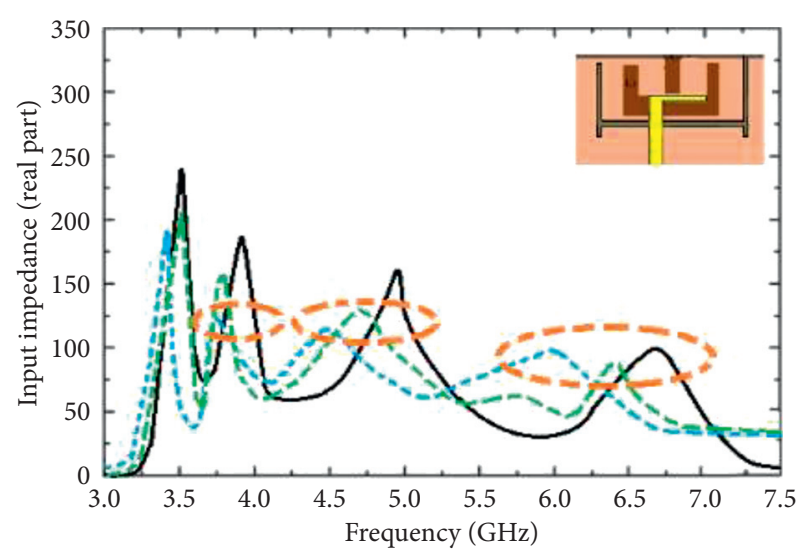

(a)

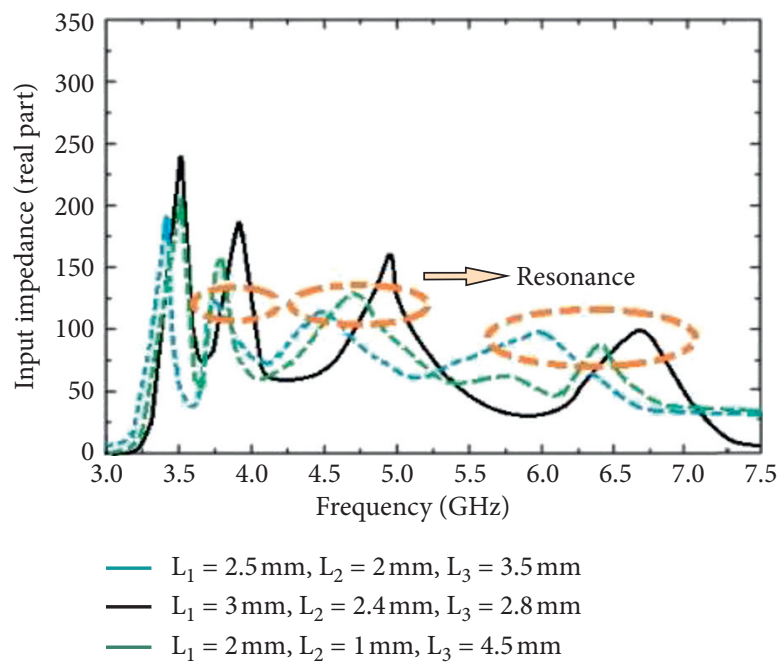

(b)

Figure 2: (a) Antenna element input impedance. (b) Antenna element input impedance with the variation of E-shaped slot.

the distribution of surface current in the absence and presence of decoupling structure is shown in Figures 3(a) and $3(\mathrm{~b})$. A comparison of the distribution of the surface current between Figures 3(a) and 3(b) shows that when the first antenna is energized and excited, the second antenna is terminated with $50 \Omega$ load, and the decoupling factor proposed here successfully precludes the surface current flowing from antenna 1 to antenna 2 . Then, in the situation of with and without decoupling components, the transmission coefficients between two pairs of antenna 1, antenna 2 , and antenna 3 were shown in Figures 4 and 5. Clearly, with the decoupling structure, the degree of element insulation is enhanced to more than $20 \mathrm{~dB}$, which is highly competitive in this regard.

\section{Results and Discussion}

4.1. S Parameters. The transmission coefficient, reflection coefficient, and $\mathrm{S}$ parameters of antenna design are discussed in the following. The MIMO antenna design which is proposed here can support a broadband range from $3.3 \mathrm{GHz}$ to $6.0 \mathrm{GHz}$ with a reflection coefficient less than $-6 \mathrm{~dB}(3: 1$ VSWR).

4.2. Transmission Coefficient. Transmission coefficient between any antenna pairs 1,2 , and 3 in the case of a decoupling element with or without the decoupling element is shown in Figures 4 and 6. It clearly shows that, without decoupling structure, the element isolation is around $-15 \mathrm{~dB}$; obviously, the insulation of the elements is enhanced by more than $-20 \mathrm{~dB}$ with the aid of decoupling structure. The reflection coefficient between the ports $S_{21}, S_{32}, S_{51}$, and $S_{62}$ was analyzed because ports 1 and 2, 2 and 3, 1 and 5, and 2 and 6 are adjoining to one another and as well the coupling among them is more powerful than the other pair. The simulated values fit well, and the isolation of the element exceeds $-20 \mathrm{~dB}$ in the target frequency band.
Simulated results of antenna efficiency are shown in the following; Figure 7 clearly shows that the effectiveness of the antenna is greater than $80 \%$ on all target frequency bands.

The envelope correlation coefficient (ECC) of the system proposed in this section was analyzed. ECC is an important consideration in accessing the multiplexing and the diversity of the MIMO antenna system. Figure 8 represents the virtual ECC of antenna pairs 1 and 2,2 and 3,1 and 5, and 2 and 6. The pairs of antennas are preferred, as they are close to one another. For simplicity's sake, the envelope correlation coefficient of the pair of antennas, which is in a symmetrical manner, is not included here. In the above figure, ECC in the targeted frequency range is lower than 0.04 , offering a promising output.

4.3. Performance Metrics on Radiation Pattern. In this section, the radiation pattern of antenna 1 and the radiation pattern of antenna 2 were analyzed. Instead of the symmetrical MIMO layout, the radiation models of other antenna components of the antenna system are not included for simplicity here. The simulated 3D radiation patterns of antenna 1 operated at three different frequencies like $3.5 \mathrm{GHz}, \quad 4.5 \mathrm{GHz}$, and $5.5 \mathrm{GHz}$ are represented in Figure 9 (a) and $3 \mathrm{D}$ radiation patterns of antenna 2 operated at three different frequencies like $3.5 \mathrm{GHz}, 4.5 \mathrm{GHz}$, and $5.5 \mathrm{GHz}$ are represented in Figure 9(b), respectively. Figures 9(a) and 9(b) show that antenna 1's maximal radiation path is inclined and indicating the third quadrant or clock face is at $3.5 \mathrm{GHz}$; antenna 1 antenna patterns are skewed at $4.5 \mathrm{GHz}$ and $5.5 \mathrm{GHz}$, too. The justification is that, for antenna 1, the field is asymmetrical. And in Figure 9(b), antenna 2's radiation variations appear more symmetric around the frequency range than those of antenna 1. In fact, the ground of antenna 2 is relatively symmetrical in relation to the ground of antenna 1 . Consequently, the overall radiation paths of antenna 1 and antenna 2 do not point through the frequency band to each other, resulting in a respectable ECC of less than 0.04 . 


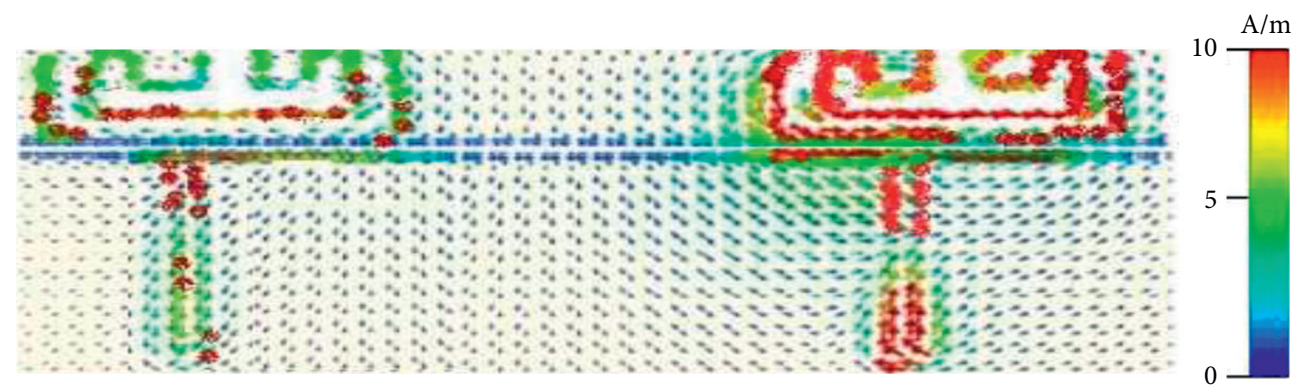

(a)

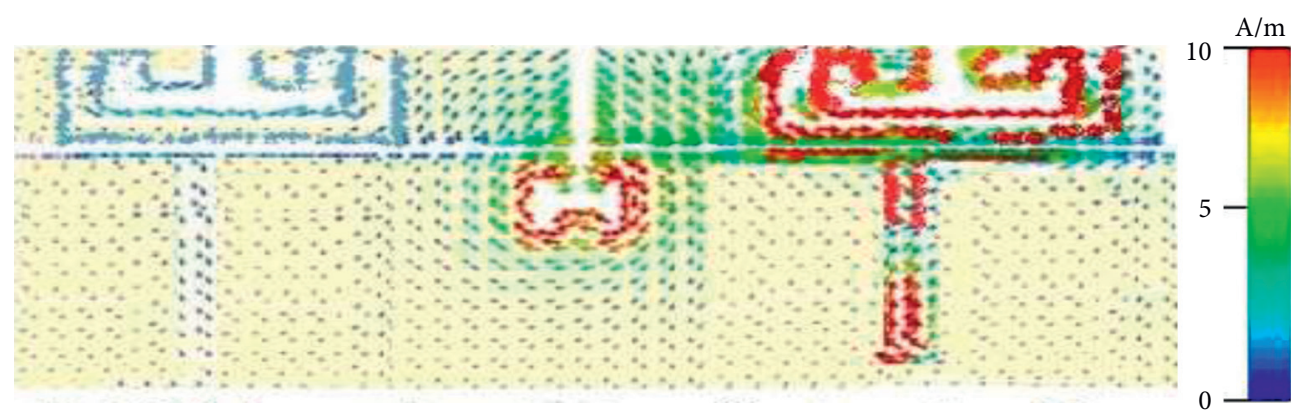

(b)

Figure 3: (a) Absence of decoupling structure between antennas 1 and 2. (b) Presence of decoupling structure between antennas 1 and 2.

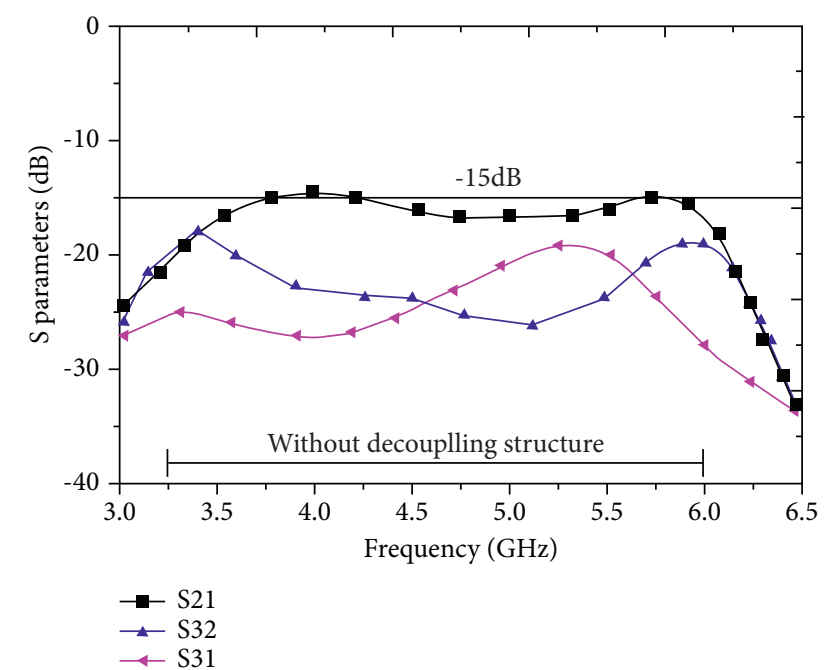

FIgURE 4: Transmission coefficient without decoupling structure.

\subsection{Performances of MIMO Antenna.}

\section{Impacts on Operators Hand and Head Style}

Finally, Section 5 shows the influence of the one-hand model, double-hand model, and operator's head-hand model. In multiple cases, the propagation coefficient, variance of reflection coefficients, and radiation efficiencies were investigated, respectively. In Figure 10 along with its subsections ( $a, b, c$, and $d$ ), the one-hand model simulates the MIMO antenna system. Although the adequacy of the impedance to the lower frequency band has deteriorated slightly, all antennas are still able to cover $3.3-6.0 \mathrm{GHz}$.

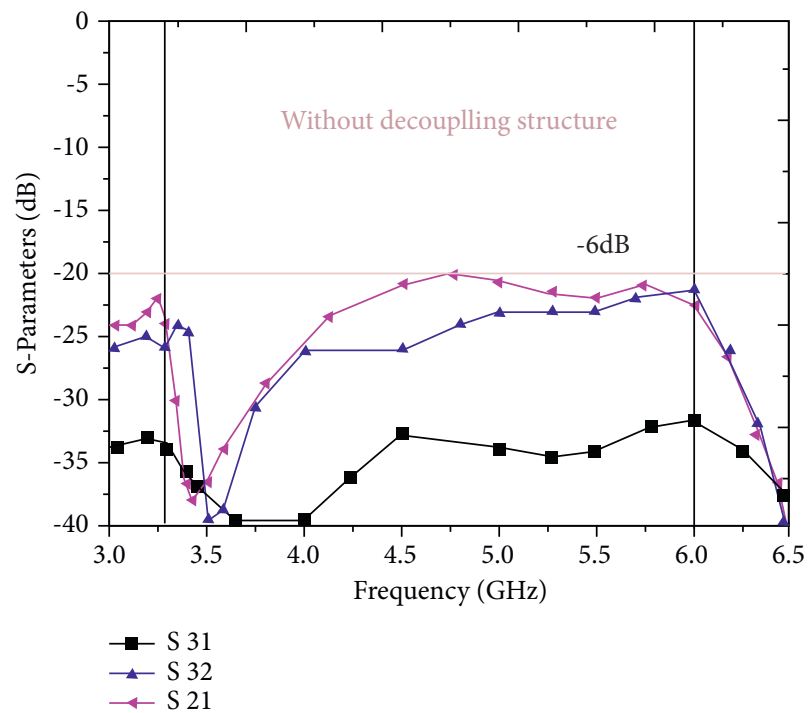

FIGURE 5: Transmission coefficient with decoupling structure.

The isolation of the components remains over $20 \mathrm{~dB}$. Their radiation efficiencies decreased dramatically due to antennas 1-2's direct finger touch, although the efficiencies of antennas 3 to 8 remain higher than $60 \%$ in the target frequency range. In Figure 11 along with its subsections (a, b, c, and d), with a dual-hand model, the MIMO array antenna system is simulated. Thumbs are influenced by antennas 5 and 8 , resulting in the balancing of degenerate impedance and radiation quality. Nevertheless, the isolation of the element is over $20 \mathrm{~dB}$ and performance is above 60 percent; antennas 1, 2, 3, 4, 6, and 7 and 8 still operate at $3.3-6.0 \mathrm{GHz}$. 


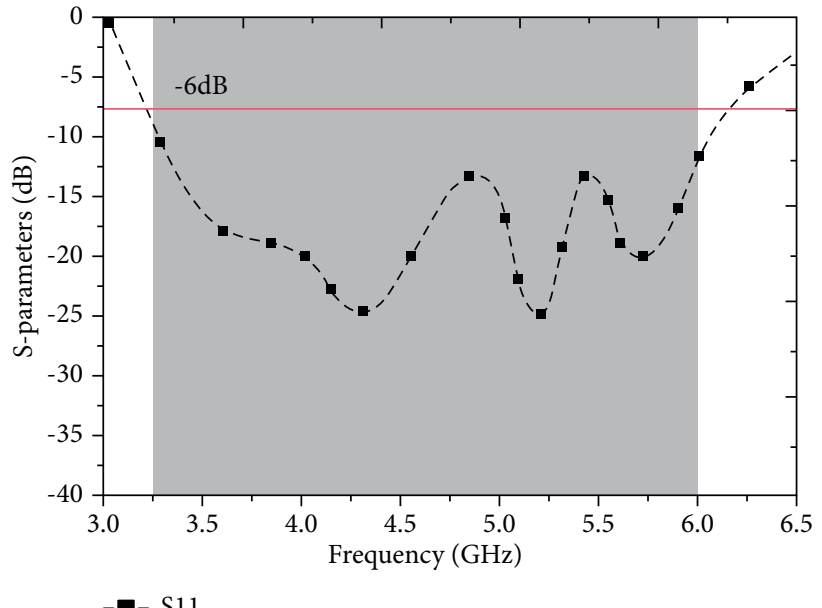

FIGURE 6: Simulated reflection coefficients.

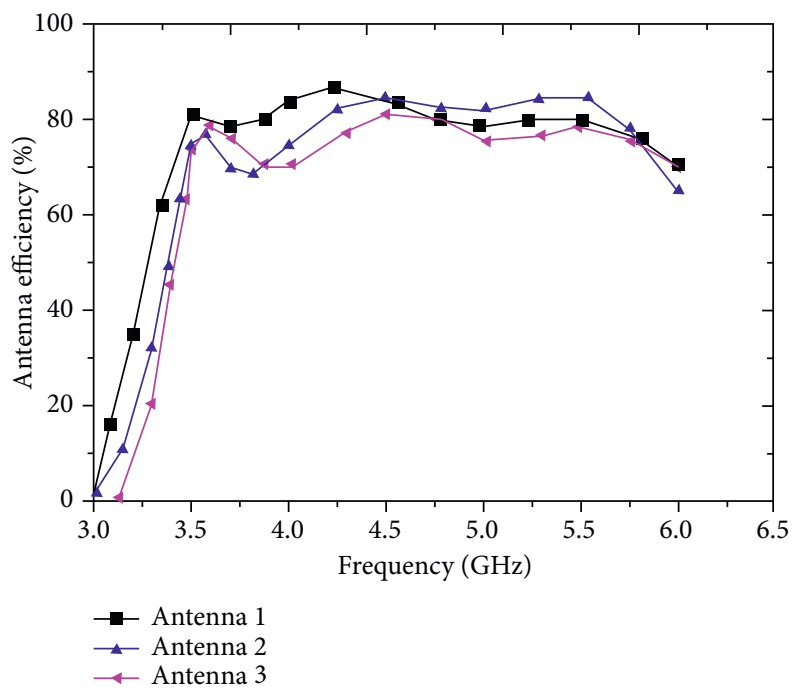

FIgURE 7: Simulated result of antenna efficiency.

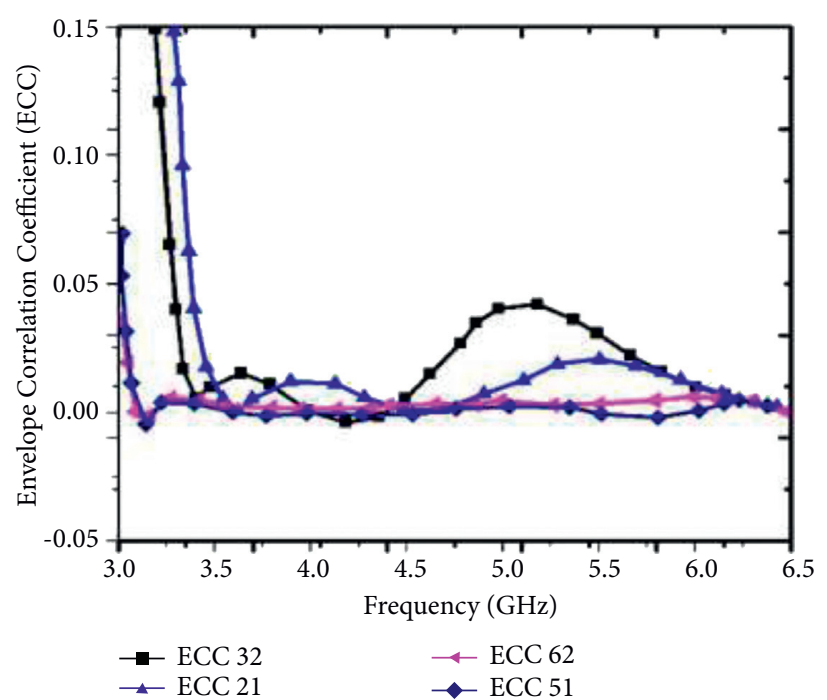

Figure 8: Simulated envelope correlation coefficient result (ECC). 

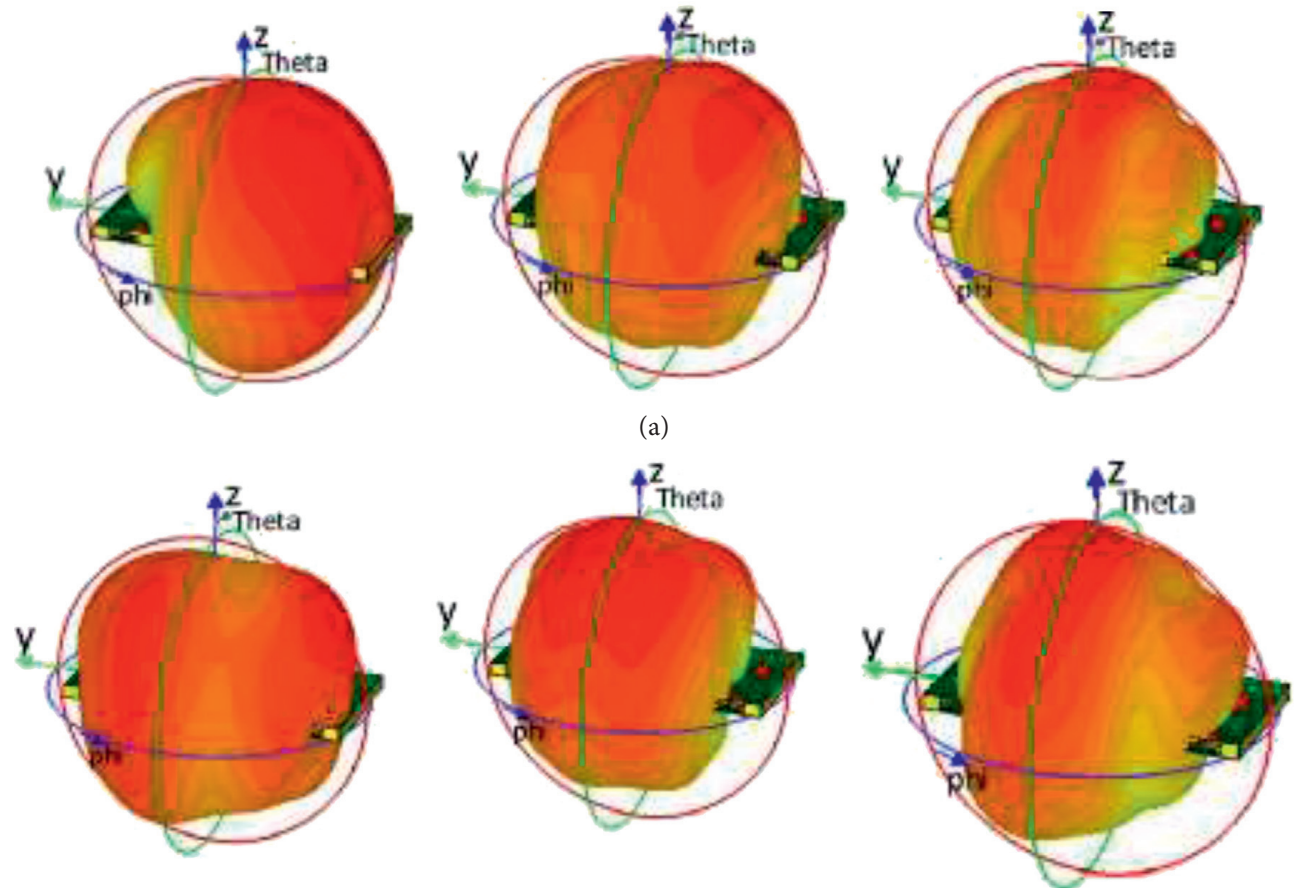

(b)

Figure 9: (a) 3D radiation pattern for antenna 1 simulated at $3.5 \mathrm{GHz}, 4.5 \mathrm{GHz}$, and $5.5 \mathrm{GHz}$. (b) 3D radiation pattern for antenna 2 simulated at $3.5 \mathrm{GHz}, 4.5 \mathrm{GHz}$, and $5.5 \mathrm{GHz}$.

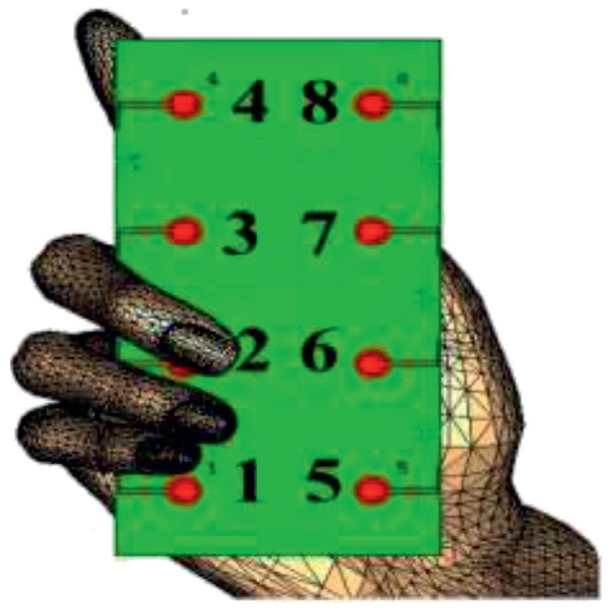

(a)

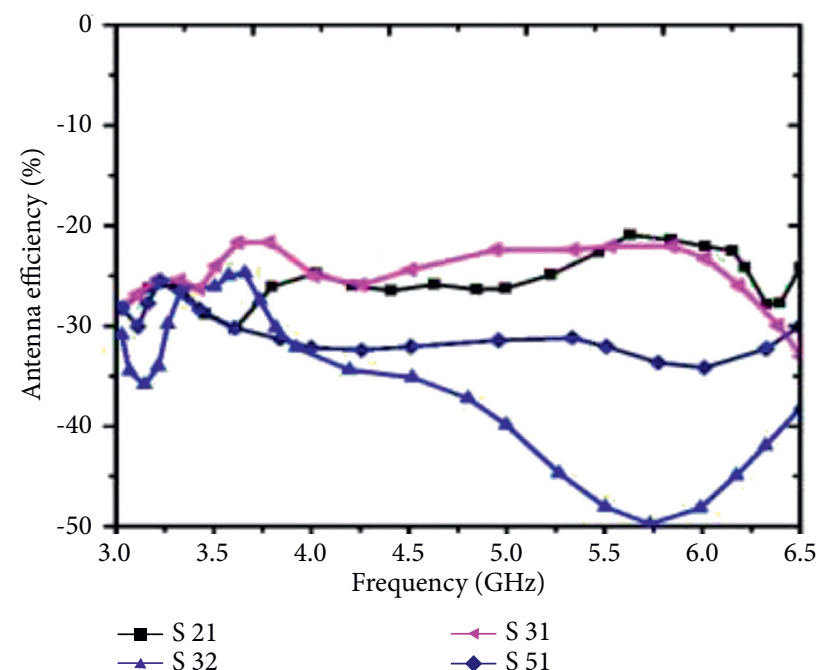

(b)

Figure 10: Continued. 


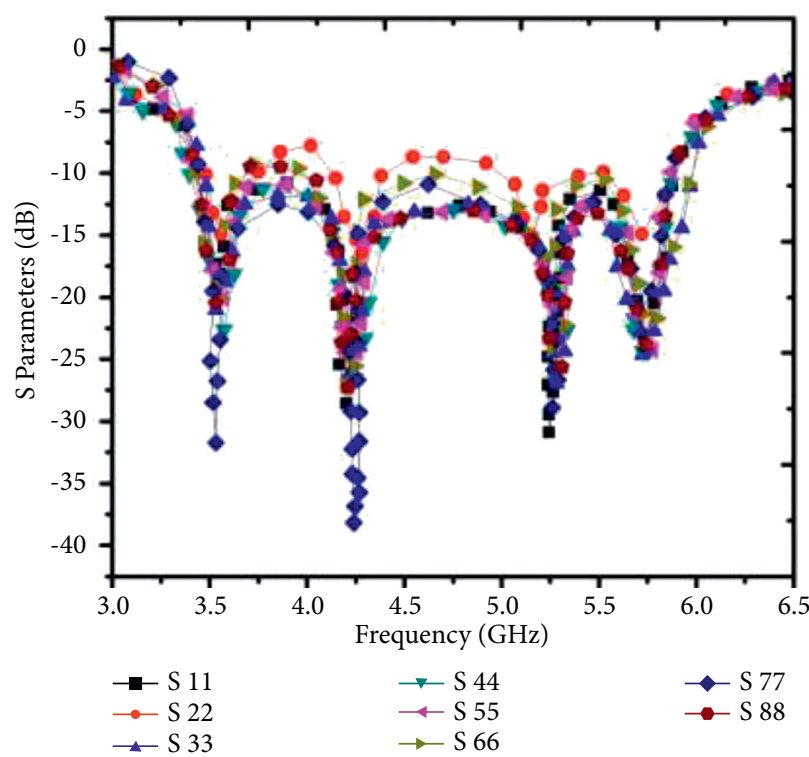

(c)

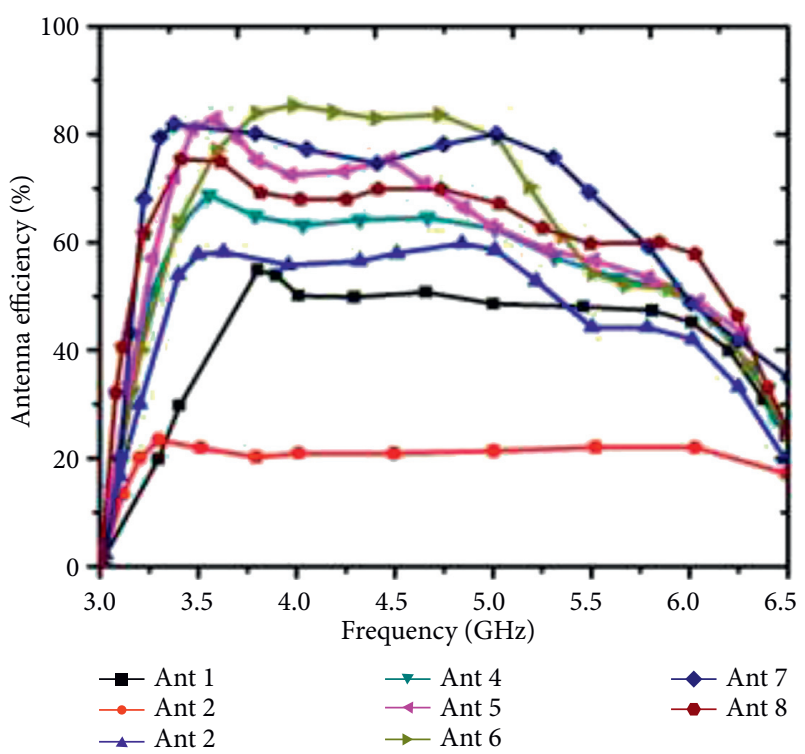

(d)

Figure 10: (a) One-hand model. (b) One-hand model's transmission coefficient. (c) One-hand model's reflection coefficient. (d) One-hand model's antenna efficiency.
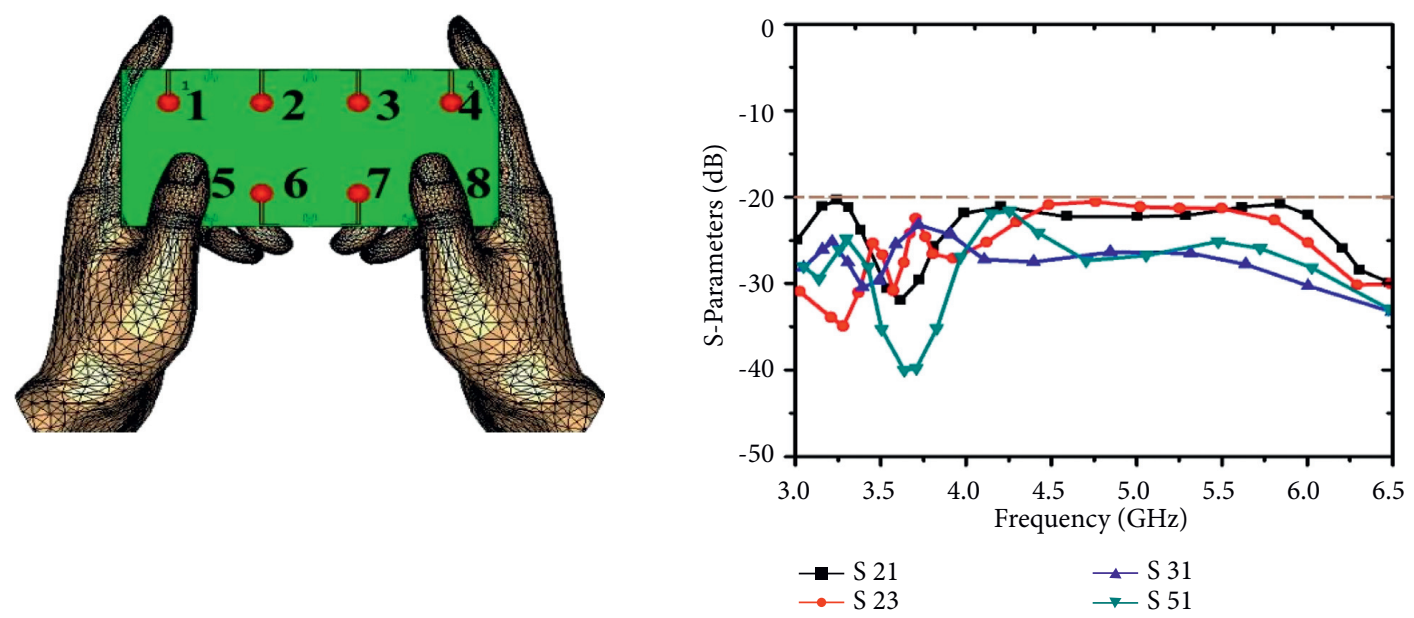

(a)

(b)

Figure 11: Continued. 


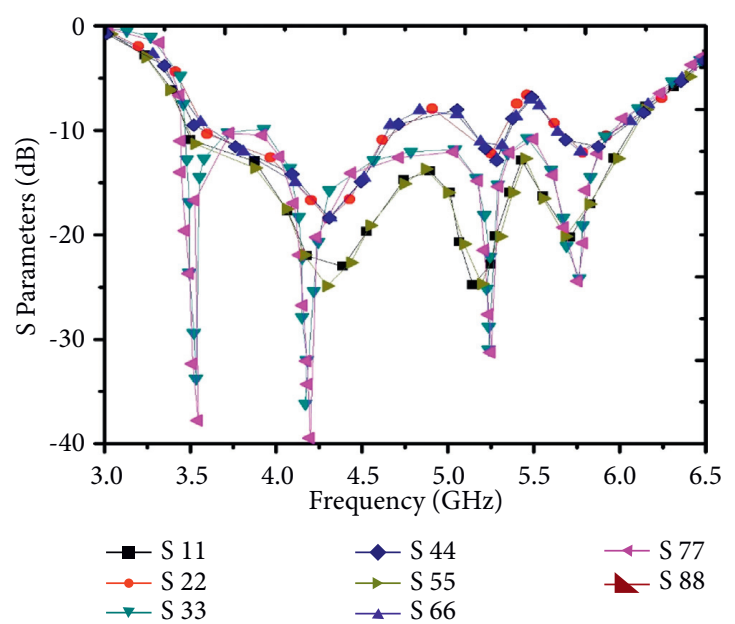

(c)

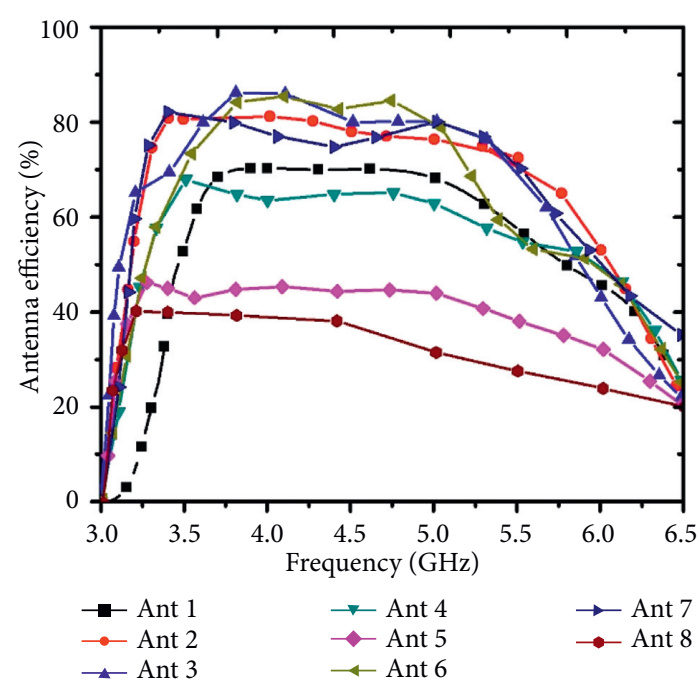

(d)

Figure 11: (a) Double-hand model. (b) Transmission coefficient of double-hand model. (c) Reflection coefficient of double-hand model. (d) Antenna efficiency of double-hand model.

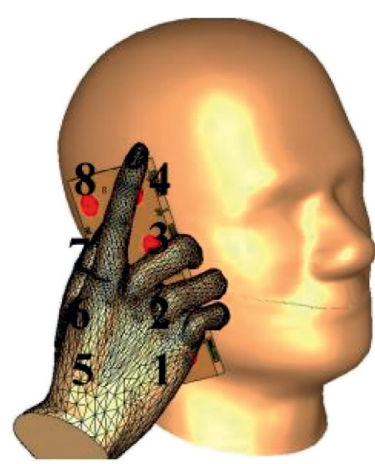

(a)

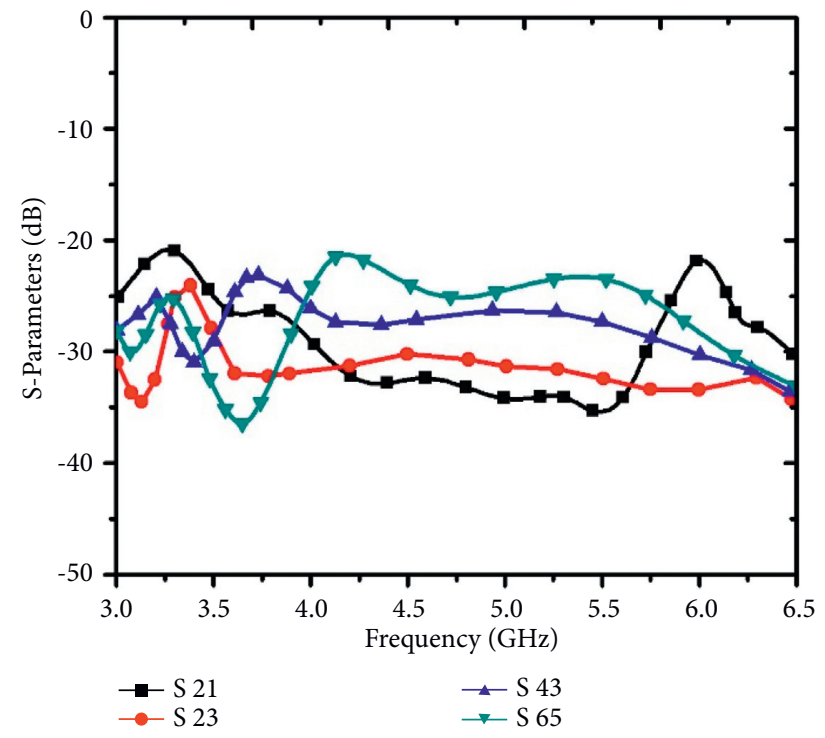

(b)

FIgURE 12: Continued. 


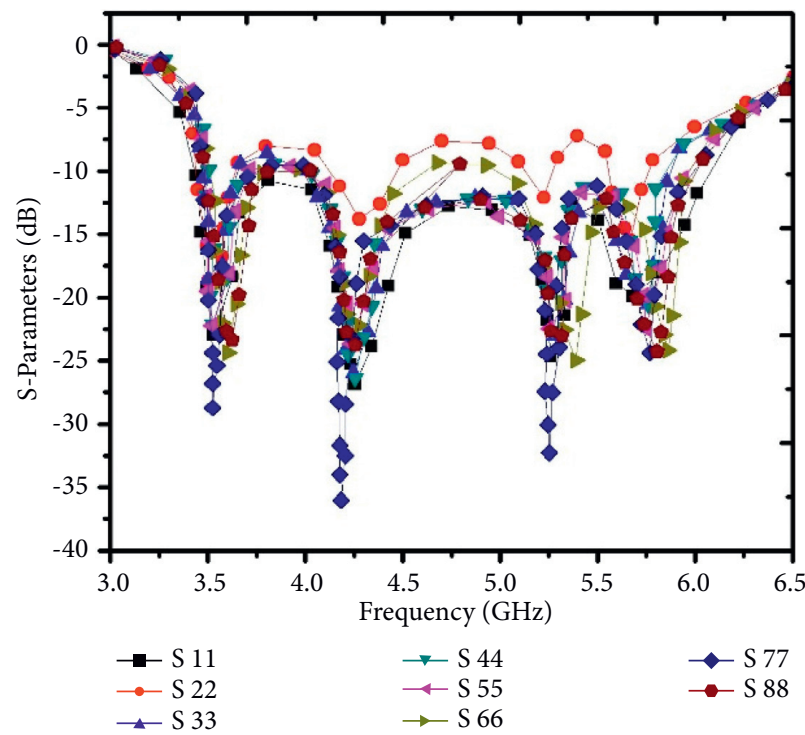

(c)

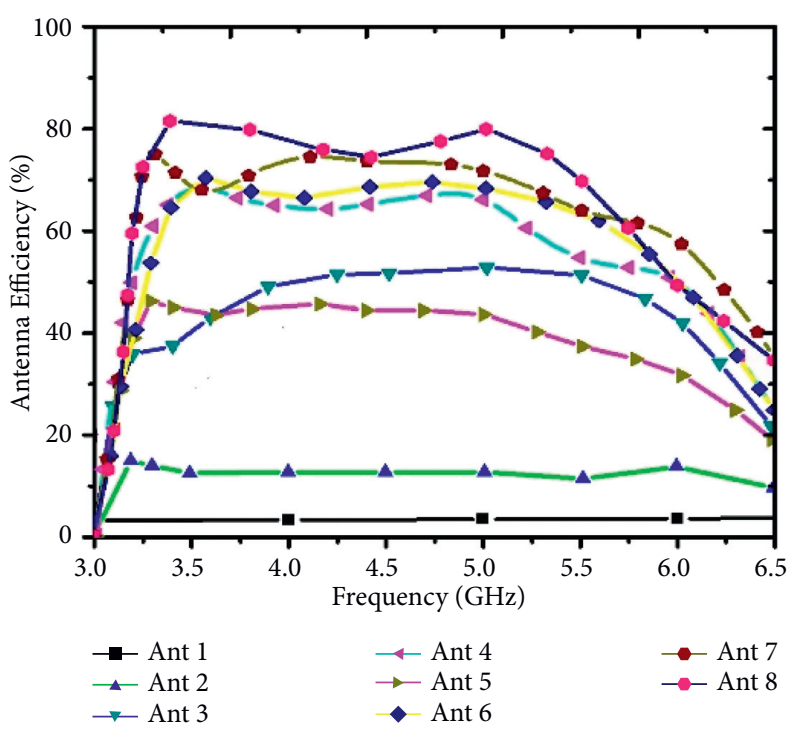

(d)

Figure 12: (a) Head-hand model. (b) Transmission coefficient of head-hand model. (c) Reflection coefficient of head-hand model. (d) Antenna efficiency of head-hand model.

In Figure 12 along with its subsections ( $a, b, c$, and $d$ ), a head-hand model simulates the MIMO antenna system. The coefficients of reflection remain constant, and the isolation of the element remains 20 decibels. In comparison, certain antennas' radiation efficiencies were reduced because a portion of radiated energy was consumed by the hand and head versions. As a consequence, the efficiencies of antennas 2,3 , and 5 are less than $60 \%$, the efficiencies of antenna 8 are around $60 \%$, and the efficiencies of antennas $1,4,5,6$, and 7 are even more than $60 \%$. The proposed wideband MIMO antenna device demonstrates reasonably good isolation and low envelope correlation coefficient, both of which are pretty good for the fifth-generation MIMO antenna application. The calculated findings show that the planned antenna array's operating frequency range is capable of covering 3.3 to $6 \mathrm{GHz}$, with over $20 \mathrm{~dB}$ isolation. The antenna will guarantee that the ECC level is smaller than 0.04. The proposed MIMO antenna technology is also efficient for mobile terminal $5 \mathrm{G}$ applications. In the future, research will be improved further by including various multioutput signal parameters with antenna efficiency.

\section{Conclusion}

In this work, for $5 \mathrm{G}$ mobile applications, an eight-part MIMO array antenna system is planned. The fifth-generation MIMO array antenna can operate properly using a portion of the metal frame. It was verified by simulation that it is possible to achieve the suggested antenna with effective antenna isolation using the decoupling technique. In specific, the proposed wideband MIMO antenna device demonstrates reasonably good isolation and low envelope correlation coefficient, both of which are pretty good for fifth-generation MIMO antenna application. The calculated findings show that the planned antenna array's operating frequency range is capable of covering 3.3 to $6 \mathrm{GHz}$, with over $20 \mathrm{~dB}$ isolation. The antenna will guarantee that the ECC level is smaller than 0.04. The proposed MIMO antenna technology is also efficient for mobile terminal $5 \mathrm{G}$ applications.

\section{Data Availability}

All data are available within the manuscript.

\section{Conflicts of Interest}

The authors declare that they have no conflicts of interest.

\section{References}

[1] L. Sun, Y. Li, Z. Zhang, and Z. Feng, "Wideband 5G MIMO antenna with integrated orthogonal-mode dual-antenna pairs for metal-rimmed smartphones," IEEE Transactions on Antennas and Propagation, vol. 68, no. 4, pp. 2494-2503, 2020.

[2] J. G. Andrews, S. Buzzi, W. Choi et al., "What will 5G be?" IEEE Journal on Selected Areas in Communications, vol. 32, no. 6, pp. 1065-1082, 2014.

[3] M. A. Jensen and J. W. Wallace, "A review of antennas and propagation for MIMO wireless communications," IEEE Transactions on Antennas and Propagation, vol. 52, no. 11, pp. 2810-2824, 2004.

[4] X.-T. Yuan, W. He, K.-D. Hong, C.-Z. Han, Z. Chen, and T. Yuan, "Ultra-wideband MIMO antenna system with high element-isolation for $5 \mathrm{G}$ smartphone application," IEEE Transactions, vol. 8, 2020.

[5] S. Neelakandan and J. Gokul Anand, "Trust based optimal routing in MANET's," in Proceedings of the 2011 International Conference on Emerging Trends in Electrical and Computer Technology, pp. 1150-1156, Nagercoil, India, March 2011.

[6] B. S. Virdee, A. A. Althuwayb, D. Mariyanayagam, and E. Limiti, "Compact and low-profile on-chip antenna using 
underside electromagnetic coupling mechanism for terahertz front-end transceivers," Electronics, vol. 10, Article ID 1264, 2021.

[7] A. A. Althuwayb, M. Alibakhshikenari, B. S. Virdee, H. Benetatos, F. Falcone, and E. Limiti, "Antenna on chip (AoC) design using metasurface and SIW technologies for $\mathrm{THz}$ wireless applications," Electronics, vol. 10, no. 9, 1120 pages, 2021.

[8] B. S. Virdee and S. Salekzamankhani, "High-isolation antenna array using SIW and realized with a graphene layer for subterahertz wireless applications," Scientific Reports, vol. 11, Article ID 10218, 2021.

[9] M. Alibakhshikenari, B. S. Virdee, M. Khalily et al., "Highgain on-chip antenna design on silicon layer with aperture excitation for terahertz applications," IEEE Antennas and Wireless Propagation Letters, vol. 19, no. 9, pp. 1576-1580, 2020.

[10] S. Zhang, A. A. Glazunov, Z. Ying, and S. He, "Reduction of the envelope correlation coefficient with improved total efficiency for mobile LTE MIMO antenna arrays: mutual scattering mode," IEEE Transactions on Antennas and Propagation, vol. 61, no. 6, pp. 3280-3291, 2013.

[11] L. Zhao and K.-L. Wu, "A dual-band coupled resonator decoupling network for two coupled antennas," IEEE Transactions on Antennas and Propagation, vol. 63, no. 7, pp. 2843-2850, 2015.

[12] A. Zhao and Z. Ren, "Size reduction of self-isolated MIMO antenna system for $5 \mathrm{G}$ mobile phone applications," IEEE Antennas and Wireless Propagation Letters, vol. 18, no. 1, pp. 152-156, 2019.

[13] C. F. Ding, X. Y. Zhang, C.-D. Xue, and C.-Y.-D. Sim, "Novel pattern-diversity-based decoupling method and its application to $\mathrm{m}$ antenna," IEEE Transactions on Antennas and Propagation, vol. 66, no. 10, pp. 4976-4985, 2018.

[14] M. S. Khan, A. D. Capobianco, A. Naqvi, B. Ijaz, S. Asif, and B. D. Braaten, "Planar, compact ultra-wideband polarisation diversity antenna array," IET Microwaves, Antennas \& Propagation, vol. 9, no. 15, pp. 1761-1768, 2015.

[15] K.-L. Wong, C.-Y. Tsai, and J.-Y. Lu, "Two asymmetrically mirrored gap-coupled loop antennas as a compact building block for eight-antenna MIMO array in the future smartphone," IEEE Transactions on Antennas and Propagation, vol. 65, no. 4, pp. 1765-1778, 2017.

[16] K.-L. Wong, J.-Y. Lu, L.-Y. Chen, W.-Y. Li, and Y.-L. Ban, "8antenna and 16-antenna arrays using the quad-antenna linear array as a building block for the 3.5-GHz LTE MIMO operation in the smartphone," Microwave and Optical Technology Letters, vol. 58, no. 1, pp. 174-181, 2016.

[17] W. Jiang, B. Liu, Y. Cui, and W. Hu, "High-isolation eightelement MIMO array for 5G smartphone applications," IEEE Access, vol. 7, pp. 34104-34112, 2019.

[18] Y. Wang and Z. Du, "A wideband printed dual-antenna with three neutralization lines for mobile terminals," IEEE Transactions on Antennas and Propagation, vol. 62, no. 3, pp. 1495-1500, 2014.

[19] X. Rong Lin Li and R. Li, "A novel dual-band MIMO antenna array with low mutual coupling for portable wireless devices," IEEE Antennas and Wireless Propagation Letters, vol. 10, pp. 1039-1042, 2011.

[20] Y. Li, C. Y. D. Sim, Y. Luo, and G. Yang, "Multiband 10 antenna array for sub $6 \mathrm{GHz}$ MIMO applications in 5G smartphones," IEEE Access, vol. 6, 2018.

[21] J. Deng, J. Li, L. Zhao, and L. Guo, "A dual-band inverted-F MIMO antenna with enhanced isolation for WLAN applications," IEEE Antennas and Wireless Propagation Letters, vol. 16, pp. 2270-2273, 2017.

[22] Z. Li, Z. Du, M. Takahashi, K. Saito, and K. Ito, "Reducing mutual coupling of MIMO antennas with parasitic elements for mobile terminals," IEEE Transactions on Antennas and Propagation, vol. 60, no. 2, pp. 473-481, Feb. 2012.

[23] Y. Li, C.-Y.-D. Sim, Y. Luo, and G. Yang, "High-isolation 3.5 $\mathrm{GHz}$ eight-antenna MIMO array using balanced open-slot antenna element for 5G smartphones," IEEE Transactions on Antennas and Propagation, vol. 67, no. 6, pp. 3820-3830, 2019.

[24] A. B. Numan, M. S. Sharawi, A. Steffes, and D. N. Aloi, "A defected ground structure for isolation enhancement in a printed MIMO antenna system," in Proceedings of the 7th European Conference on Antennas and Propagation (EUCAP), pp. 2123-2126, Gothenburg, Sweden, April 2013.

[25] M. Alibakhshikenari, V. Mohammad, B. Singh et al., "High performance metasurface-based on-chip antenna for terahertz integrated circuits," in Proceedings of the 2020 Third International Workshop on Mobile Terahertz Systems (IWMTS), Essen, Germany, July 2020.

[26] M. Alibakhshikenari, B. S. Virdee, and B. Limiti, "Study on isolation and radiation behaviours of a $34 \times 34$ array-antennas based on SIW and metasurface properties for applications in terahertz band over 125-300 GHz," Optik-International Journal for Light and Electron Optics, 2019.

[27] M. Alibakhshikenari, B. S. Virdee, P. Shukla et al., "Isolation enhancement of densely packed array antennas with periodic MTM-photonic bandgap for SAR and MIMO systems," IET Microwaves, Antennas \& Propagation, vol. 14, no. 3, pp. $183-188,2020$.

[28] M. Alibakhshikenari, B. S. Virdee, C. H. See, R. A. AbdAlhameed, F. Falcone, and E. Limiti, "Surface wave reduction in antenna arrays using metasurface i and SAR systems," Radio Science, vol. 54, no. 11, pp. 1067-1075, 2019.

[29] M. Khalily and B. S. Virdee, "Mutual-coupling isolation using embedded metamaterial EM bandgap decoupling slab for densely packed array antennas," IEEE Access, vol. 7, pp. 51827-51840, 2019.

[30] M. Alibakhshikenari, "Mutual coupling suppression between two closely placed microstrip patches using EM-bandgap metamaterial fractal loading," IEEE Access, vol. 7, pp. 23606-23614, 2019.

[31] P. Hallbjorner, "The significance of radiation efficiencies when using S-parameters to calculate the received signal correlation from two antennas," IEEE Antennas and Wireless Propagation Letters, vol. 4, pp. 97-99, 2005.

[32] L. Sun, H. Feng, Y. Li, and Z. Zhang, "Compact 5G MIMO mobile phone antennas with tightly arranged orthogonalmode pairs," IEEE Transactions on Antennas and Propagation, vol. 66, no. 11, pp. 6364-6369, 2018.

[33] L. Zhao, K.-W. Qian, and K.-L. Wu, “A cascaded coupled resonator decoupling network for mitigating interference between two radios in adjacent frequency bands," IEEE Transactions on Microwave Theory and Techniques, vol. 62, no. 11, pp. 2680-2688, 2014.

[34] Y. Liu, A. Ren, H. Liu, H. Wang, and C.-Y.-D. Sim, "Eightport MIMO array using characteristic mode theory for $5 \mathrm{G}$ smartphone applications," IEEE Access, vol. 7, pp. 4567945692, 2019.

[35] A. Zhao and Z. Ren, "Wideband MIMO antenna systems based on coupled-loop antenna for 5G N77/N78/N79 applications in mobile terminals," IEEE Access, vol. 7, pp. 93761-93771, 2019. 
[36] M. Gallo, E. Antonino-Daviu, M. Ferrando-Bataller, M. Bozzetti, J. M. Molina-Garcia-Pardo, and L. Juan-Llacer, "A broadband pattern diversity annular slot antenna," IEEE Transactions on Antennas and Propagation, vol. 60, no. 3, pp. 1596-1600, 2012.

[37] S. Zhang, B. K. Lau, A. Sunesson, and S. He, "Closely-packed UWB MIMO/diversity antenna with different patterns and polarizations for USB dongle applications," IEEE Transactions on Antennas and Propagation, vol. 60, no. 9, pp. 4372-4380, 2012.

[38] Y. C. Lu and Y. C. Lin, "A compact dual-polarized UWB antenna with high port isolation," in Proceedings of the IEEE Antennas Propagation Society International Symposium (APSURSI, 2010), Toronnto, Canada, July 2010.

[39] G. Adamiuk, S. Beer, W. Wiesbeck, and T. Zwick, "Dualorthogonal polarized antenna for UWB-IR technology," IEEE Antennas and Wireless Propagation Letters, vol. 8, pp. 981984, 2009.

[40] E. Antonino-Daviu, M. Gallo, B. Bernardo-Clemente, and M. Ferrando-Bataller, "Ultra-wideband slot ring antenna for diversity applications," Electronics Letters, vol. 46, no. 7, pp. $478-480,2010$.

[41] H. Xu, H. Zhou, S. Gao, H. Wang, and Y. Cheng, "Multimode decoupling technique with independent tuning characteristic for mobile terminals," IEEE Transactions on Antennas and Propagation, vol. 65, no. 12, pp. 6739-6751, Dec. 2017.

[42] D. Paulraj, "An automated exploring and learning model for data prediction using balanced CA-SVM," Journal of Ambient Intelligence and Humanized Computing, vol. 12, no. 5, 2020.

[43] M. A. Berlin and S. Tripathi, "IoT-based traffic prediction and traffic signal control system for smart city," Soft Computing, vol. 25,2021 